\title{
Correction to: The ultrasonographic study of the nail reveals differences in patients affected by inflammatory and degenerative conditions
}

\author{
Luca Idolazzi $^{1}$ (I) $\cdot$ Alen Zabotti $^{2} \cdot$ Angelo Fassio $^{1} \cdot$ Enzo Errichetti $^{3} \cdot$ Camilla Benini $^{1} \cdot$ Elisabetta Vantaggiato ${ }^{1}$. \\ Maurizio Rossini ${ }^{1}$. Salvatore De Vita ${ }^{2}$. Ombretta Viapiana ${ }^{1}$
}

Published online: 14 January 2020

(C) International League of Associations for Rheumatology (ILAR) 2020

\section{Correction to: Clinical Rheumatology (2019) 38:913-920} https://doi.org/10.1007/s10067-019-04437-0

The original published version of this article contained an incorrect Table 2.

The correct Table 2 shown as follows:
Table 2 alterations regarding qualitative and semi quantitative parameters of the nail, joint and enthesis complex

\begin{tabular}{lllllll}
\hline & & PSO & PSA & RA & OA & HC \\
\hline PDUS Nail Bed Case count & Absent & 14 & 21 & 17 & 6 & $38^{\wedge}$ \\
& Mild & 9 & 16 & 8 & 12 & 9 \\
& Moderate & 1 & 9 & 7 & 9 & 2 \\
& Severe & 7 & 5 & 5 & 7 & 1 \\
PDUS enthesis Case count & Absent & 20 & 23 & $35^{\wedge}$ & 25 & $48^{\wedge}$ \\
& Present & 11 & $28^{*}$ & 2 & 9 & 2 \\
\hline
\end{tabular}

PDUS: power Doppler ultrasonography signal

*residual value significant with a trend which differs from the standard behaviour towards a pathological feature

$\wedge$ residual value significant with a trend which differs from the standard behaviour towards a normal feature
The online version of the original article can be found at https://doi.org/ 10.1007/s10067-019-04437-0

Luca Idolazzi

luca.idolazzi@univr.it

1 Rheumatology Unit, Department of Medicine, University of Verona, Piazzale A. L. Scuro 1, 37138 Verona, Italy

2 Department of Medical and Biological Sciences, Rheumatology Clinic, University of Udine, Udine, Italy

3 Department of Experimental and Clinical Medicine, Institute of Dermatology, University of Udine, Udine, Italy 